\title{
DISCURSO CREADOR Y DISTANCIA TEMPORAL LA EXPRESIÓN DEL TIEMPO EN RICGEUR
}

\author{
Mercedes Laguna González \\ https://orcid.org/0000-0002-6868-9444 \\ Universidad de Granada \\ bttps://doi.org/10.15304/ag.40.2.7153
}

\section{Resumen}

Comentamos en este artículo tres conferencias de Paul Ricœur: dos sobre la imaginación y la metáfora (una de ellas inédita), y una tercera sobre la escritura de la historia y la representación del pasado. El objetivo es establecer las relaciones entre tiempo y palabra a cuenta del discurso creador, que nace de la imaginación productora y que, a su vez, puede ser capaz de expresar el ser finito y temporal que somos. El discurso creador (que se expresa mediante figuras temporales), propio de la poesía y de la narración, es también decisivo para la elaboración del quehacer historiográfico, tanto en el proceso de investigación documental, como en el planteamiento de las preguntas sobre los distintos acontecimientos históricos, y, propiamente, para la escritura de la historia.

Palabras clave: Paul Ricœur, discurso creador, tiempo, condición temporal, escritura de la historia.

\begin{abstract}
In this paper I examine three lectures by Paul Ricœur: two about imagination and the metaphor (one of them unpublished), and a third one about the writing of history and the representation of the past. The objective is to establish the connections between time and word on account of the creative speech; this creative speech is born from the productive imagination and, at the same time, it may be able to express the finite and temporary being that we are. The creative speech, which is expressed through temporary figures, typical of poetry and narrative, is also decisive for historiographic work, both in the process of
\end{abstract}

Recibido: 05/10/2020. Aceptado: 09/03/2021. 
documentary research, and in the posing of questions about historical events, and, therefore, for the writing of history.

Keywords: Paul Ricœur, creative speech, time, temporary condition, writing of the history.

\section{El discurso creador: imaginación, lenguaje y tiempo}

Ricœur es, ante todo, un pensador dialogante, abierto; un científicohumanista interdisciplinar, lector incansable, que ejerce de comentador-interpretador de textos para construir una escritura filosófica novedosa, pero enraizada en las fuentes. La filosofía de Ricœur, con sus ramas - la filosofía del lenguaje y la literatura, la filosofía de la historia, la ontología, la antropología, la ética - tiene valor y es digna de ser escuchada y tenida en cuenta porque nace del diálogo, de la imbricación con las otras ramas del saber y con los otros estilos de hacer filosofía.

Su filosofía del lenguaje ${ }^{1}$, por ejemplo, nace y crece uniendo el estructuralismo y la filosofía analítica, incorporando, además, el saber fenomenológico. Sin embargo, al mismo tiempo, Ricœur hace girar todo en torno a sus preguntas recurrentes; interpreta los hallazgos de las lecturas a la luz de los hilos fundamentales de su pensamiento. Uno de estos hilos fundamentales es el tiempo, mejor diremos, la condición temporal del ser.

En 1981, Paul Ricœur aceptó la invitación a unas Jornadas de la sociedad francesa de psicopatología de la expresión en Lille. La aportación del filósofo fue una conferencia titulada "Imaginación y metáfora". El texto fue publicado en la Revue de Psychologie Médicale, en 1982. ¿Por qué es importante detenerse en estos datos? Fundamentalmente, porque Ricœur es un filósofo de la práctica, de las actuaciones reales, a las que brinda la ayuda de la reflexión filosófica, elaborada a través de reflexiones sobre las distintas ciencias y las distintas corrientes filosóficas.

En esta ocasión, se trataba de responder a cuestiones prácticas sobre dificultades psicológicas (también sociales) de la expresión: cuestiones problemáticas sobre la comunicación humana, que, en opinión de Ricœur, podían recibir luz de su teoría de la metáfora y, a través de ella, de su pensamiento sobre la imaginación.

Nos interesa detenernos en las cuestiones de la metáfora y de la imaginación porque, a mi juicio, no solo están ligadas con la problemática

1 Barros de Oliveira ha publicado recientemente un estudio riguroso y sugerente sobre la filosofía del lenguaje de Ricœur (2020). 
filosófica del tiempo (el tema que vertebra nuestra investigación), sino porque es nuestra condición temporal — como seres humanos- la que pone en marcha los resortes de la imaginación, tanto en la metáfora de la poesía como en la puesta en intriga de la narración; tanto en la creación literaria como en la historia.

Frente a la mera imaginación reproductora — que se apoya en la percepción ${ }^{2}$ - la imaginación productora consigue "la producción de algo irreal, como en el caso de los modelos científicos, las ficciones literarias, las representaciones religiosas" (Ricœur, 1982, p. 2). Esta producción requiere — por parte de la imaginación- un trabajo de síntesis del juicio (según la enseñanza de Kant en la Critica de la razón pura). Para Ricœur, lo fundamental es el modo de la producción del sentido. Por este camino, subraya la afinidad de la imaginación productora con el lenguaje, "por su capacidad de dejarse decir”. (Ricœur, 1982, p. 3). La imaginación — productora-, según Ricœur, tiene, por tanto, un carácter semántico (innovador, pero supeditado a reglas - esquemas-), que se consigue no por asociación de ideas, sino por un trabajo de síntesis, que es lo que genera sentido.

Yvon Inizan (2016) presenta la unidad de "la vasta esfera poética" en la obra de Ricœur. "La vasta esfera poética" supone un continuum entre poesía y narración que asocia las metáforas y los relatos. Se trata - siguiendo la estela de Nelson Goodman- de un pensamiento general del símbolo y del arte. Inizan parte en este estudio de la hipótesis de que en Ricœur hay un pensamiento del arte como horizonte al que apunta toda su filosofía. "La obra ricœuriana es, seguramente, un pensamiento del acto creador" (2016, p. 112).

A mi juicio, el punto de fuga al que tiende el conjunto de la obra de Paul Ricœur es la condición temporal del ser humano, así como sus formas de expresión y construcción. A diferencia de Inizan - y de otros autores, tanto del campo de la literatura, de la historia, como, incluso de la filosofíaconsidero que la obra de Ricœur no está focalizada en el relato, ni siquiera solo en la unión - como continuum - de poesía y relato. Es necesario que nos coloquemos en este camino (el de la expresión creativa), pero - para pensar el tiempo- hemos de pertrecharnos con las armas subjetivas de la memoria y la emoción, además de las armas objetivas de la medida del tiempo y el método de las ciencias humanas y sociales.

Ricœur trata el tema de la imaginación cuando habla del actuar humano, al analizar la creatividad lingüística de la metáfora y cuando reflexiona

\footnotetext{
${ }^{2}$ Y que ha sido prioritaria en los estudios de Husserl y Sartre. (Amalric, 2012, p. 116).
} 
—en varias ocasiones y a propósito de varios tipos de discursos- sobre la experiencia del tiempo.

Jean-Luc Amalric, experto en el estudio de la imaginación creadora en la obra de Ricœur, nos servirá de puerta de entrada para establecer las conexiones entre imaginación, lenguaje y tiempo en la obra de Ricœur. En su artículo sobre "La dialéctica poético-práctica de la imaginación como nudo generador de la identidad narrativa", Jean-Luc Amalric señala el "actuar en devenir" como el eje de la teoría de la imaginación de Ricœur:

La cuestión del actuar humano constituye el centro de gravedad de la teoría ricœuriana de la imaginación. Para decirlo en términos más precisos: yo creo que no hemos sopesado bien el hecho de que la imaginación poética constitutiva de nuestras identidades narrativas no toma su significación verdadera más que cuando se encuentra justamente reinscrita en el actuar en devenir de nuestra existencia concreta ${ }^{3}$. (Amalric, 2012, p. 117).

La imaginación poética que constituye nuestras identidades — la imaginación productora o creadora de la que estamos hablando en nuestro estudio- únicamente cobra su significación verdadera, dice Jean-Luc Amalric, cuando se considera dentro del actuar en devenir de nuestra existencia concreta. Se trata de la incorporación de la actividad creadora de la imaginación al campo de la filosofía práctica. Para Jean-Luc Amalric, esta reinscripción tiene dos consecuencias. En primer lugar, el ejercicio de la actividad poética de la imaginación se vincula directamente con la experiencia del cuerpo propio. Esta actividad creadora tiene "su anclaje y sus límites en esta invariante que constituye nuestra condición corporal vivida, en tanto que mediación existencial entre nosotros y el mundo" (Amalric, 2012, p. 117). La segunda consecuencia — derivada de esta- es que la actividad poética de la imaginación, como está ligada con el cuerpo propio, adquiere una dimensión temporal decisiva: "se insertan en una dialéctica de la rememoración y de la anticipación que es constitutiva de nuestra historicidad" (Amalric, 2012, p. 117). Aunque Amalric, en este punto, se refiere en concreto a las variaciones narrativas que ofrece la imaginación productora. El investigador recuerda aquí el artículo de Ricœur (1976) sobre "La

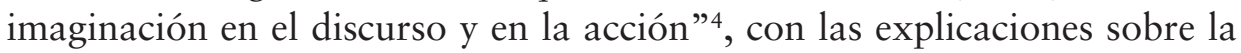

${ }^{3}$ Traducción propia.

${ }^{4}$ Paul Ricœur ya había reflexionado aquí sobre las relaciones entre la imaginación, el lenguaje y la experiencia temporal. Este texto fue su contribución para el libro colectivo Savoir, faire, espérer: les limites de la raison. En el marco de la ficción y la intersubjetividad, el filósofo francés de la hermenéutica del tiempo traza los contornos de las condiciones de posibilidad de la experiencia histórica. El artículo fue recogido más tarde en su compilación Del texto a la acción (2002) [1986]. 
característica específica de nuestra condición histórica: "la dialéctica de la rememoración de mi existencia pasada y la anticipación de mi existencia futura" (Amalric, 2012, p. 118).

\section{La expresión de la experiencia temporal en el discurso creador}

En diciembre de 1994, Paul Ricœur pronunció en la Universidad hebraica de Jerusalén una conferencia sobre "La imaginación y la regla" 5 , en el marco de la inauguración del centro de investigación sobre la cultura francesa. Esta conferencia no fue publicada por el autor ni ha sido transcrita ni editada por los investigadores del Fonds Ricoeur ${ }^{6}$ hasta la fecha.

Considero que no fue olvidada por el autor porque careciera de interés o porque sus temas parecieran expuestos ya en otros escritos anteriores. A mi juicio, en esta conferencia se produce un hito decisivo, un cambio de mirada respecto a la obra anterior del filósofo, que supone el comienzo de un nuevo cuestionamiento acerca del problema del tiempo. De hecho, es el enigma temporal el que se muestra aquí como origen de la investigación y como horizonte que pide respuestas.

Y, entonces, ¿cuál es el motivo por el que este escrito solo pronunciado no vio la luz en letras de molde? A Ricœur le interesaba transitar el camino de preguntas abierto ante él, desde los años 70, a cuenta del tiempo y la experiencia temporal. Y fue dándole cabida, ofreciendo soluciones fragmentadas- después de 1994, especialmente (aunque no solo ${ }^{7}$ ), en el libro que -en mi opinión- supone el intento de respuesta a las cuestiones planteadas al final de esta conferencia: La Mémoire, l'Histoire, l'Oubli', publicado en el año 2000.

El punto fundamental de este discurso de Ricœur es una afirmación sencilla, cotidiana, y, no obstante, pensada filosóficamente desde los inicios de la filosofía, tratada con esmero - y en especial- por Aristóteles, San Agustín, Kant, Husserl y Heidegger: la experiencia humana es esencialmente una experiencia que se desarrolla en el tiempo.

Los análisis literarios que elaboró el filósofo en Tiempo y narración —análisis profundos, acertados— serán, por mucho tiempo, de exquisita

5 "L'imagination et la règle".

${ }^{6}$ Se puede escuchar en el canal YouTube del Fonds Ricour (Ricœur, 1994).

${ }^{7}$ Veremos en este mismo estudio una publicación de Ricœur del año 2000 en una revista de estudios historiográficos.

${ }^{8}$ La Memoria, la Historia y el Olvido. 
actualidad, tanto para críticos literarios ${ }^{9}$ y lectores, como para filósofos de diferentes tendencias. Además de sus dotes estéticas, de arte imaginativo que invita a la contemplación, la literatura instruye, y lo hace con relación a la filosofía: la filosofía aprende de la literatura. (Ricœur, 1994, m. 1:57$2: 45)^{10}$.

¿Cuál es la enseñanza fundamental que puede aportar la literatura a la filosofía? Según Paul Ricœur, en el tejido-texto que supone el discurso de esta conferencia sobre la imaginación y la regla, la instrucción clave de la literatura —en cualquiera de sus géneros ${ }^{11}$ — es el acercamiento al enigma temporal, la conciencia de la distancia temporal en todos los ámbitos de la vida humana, y cómo las comunidades de interpretación, que forman las distintas asociaciones humanas, pueden ayudar a salvar esa distancia temporal.

La experiencia humana es esencialmente una experiencia que se desarrolla en el tiempo y lo que la literatura dice con más fuerza es esta vida en el tiempo. Precisamente, yo quiero mostrar cómo la poesía lírica, por una parte, y la narración, por otra, contribuyen a esta instrucción de la vida en el tiempo [...] por medio de la letra [de la escritura]. (Ricœur, 1994, m. 03:53 - 04:37).

Cuando Paul Ricœur habla del "trabajo de la metáfora" y del "trabajo del relato" está diciendo que, tanto en la poesía como en la narración, se unen de manera inextricable la imaginación creadora y la organización reglada, que supone las características formales de cada uno de estos géneros. Pero la aportación de Ricœur no se queda solo en la crítica y en la teoría literarias, sino que -inmerso en el primado de la filosofía- dice en voz alta: "por este trabajo de la metáfora, por el trabajo del relato, nuestra experiencia cotidiana, nuestra experiencia humana, se refigura y se transfigura principalmente en el enigma temporal”. (Ricœur, 1994, m. 6:48-7:14).

La imaginación - y, con ella, el lenguaje — busca de manera prioritaria la creación de sentido. El discurso creador —uniendo la imaginación y la regla- se sitúa "en el plano de la construcción interna de una inteligibilidad hablante”. (Ricœur, 1994, m. 21:40). Una inteligibilidad que parte de la sensibilidad y que expresa un proceso — un devenir- del ser.

${ }^{9}$ Unos de los mejores reconocimientos de las aportaciones de Paul Ricœur para la crítica literaria se encuentra en los escritos de Sultana Wahnón. Ver, por ejemplo, su artículo en Sociocriticism (Wahnón, 2011).

${ }^{10}$ En todo este segundo apartado, las citas recogidas de la conferencia de Ricœur son una transcripción del texto sonoro señalado. La traducción es propia en todas ellas.

${ }^{11}$ Aunque él se detiene especialmente en la poesía lírica y en la narración. 
$\mathrm{Al}$ pensar sobre el proceso de la imaginación productora, en su comunicación mediante la literatura, Paul Ricœur vuelve a la fuerza de la poiesis y a las palabras de Gaston Bachelard en La Poética del espacio (2012) ${ }^{12}$, donde el poeta sitúa el origen del lenguaje humano: en la capacidad de la imaginación poética. Con Bachelard, en la poiesis del espacio, Ricœur se reencuentra con el ser humano en devenir, un ser que es capaz de expresarse mediante la imagen creadora. La expresión que resulta es, a su vez, la expresión del devenir del $\operatorname{ser}^{13}$ (un ser que se va haciendo en el tiempo):

[...] La imagen, en lugar de ser tratada como un átomo del pensar, en lugar de ser tratada como un rasgo de sensación, de percepción, la considero como el nacimiento mismo del lenguaje. Y mi referencia será aquí el bello texto de Bachelard en $\mathrm{La}$ Poética del espacio. Cuando él dice "la imagen poética nos conduce al origen del ser hablante, la imagen se convierte en un ser nuevo de nuestro lenguaje; ella nos expresa, haciéndonos lo que ella expresa, dicho de otra manera, es a la vez un devenir de expresión y la expresión de un devenir del ser. (Ricœur, 1994, m. 17:10-18:49).

Propongo - en esta relectura de la obra de Ricœur-que se puede establecer un paralelismo entre el derribo de la incompatibilidad de dos campos semánticos extraños, que supone la metáfora, y el acercamiento al presente de los tiempos distintos (el pasado, el futuro, y el presente ampliado en el que vivimos, pensamos, sentimos y nos construimos en proceso). Por ejemplo, ahora no estoy en mi pasado ni, por supuesto, en el pasado de otros, y nunca he estado en el pasado que se intenta recuperar — de algún modoen la historia. Recuperar el pasado desde el presente, con imaginación ${ }^{14}$ y reglas específicas, es el modo de recuperar la distancia temporal que la memoria, en un plano personal, y la comunidad, en el plano colectivo, ayudan a conseguir.

Mi idea en esta exposición es decir que hay un parentesco profundo entre el tipo de trabajo que está en funcionamiento en la producción de una metáfora viva, como dije en mi ensayo ${ }^{15}$, y por otra parte en la producción de una intriga. En los dos casos, tenemos que hacer lo que yo me he arriesgado llamar, de manera general, la síntesis de lo heterogéneo. Lo heterogéneo que se puede referir a lo heterogéneo de los acontecimientos, lo heterogéneo de las intenciones, de las causas materiales, de los azares.

${ }^{12}$ La poétique de l'espace [1957].

${ }^{13}$ Marcelino Agís Villaverde define de este modo la filosofía de Ricœur: "Su filosofía responde a un proyecto de reconstrucción del sujeto a través de los discursos que le sirven de expresión: símbolos, mitos, textos, figuras del lenguaje, tramas narrativas. Al mismo tiempo, el sujeto se construye a sí mismo también con el otro y sus manifestaciones discursivas” (2006, p. 43).

${ }^{14}$ El papel de la imaginación en el quehacer historiográfico ha sido estudiado por E. Lythgoe (2014).

${ }^{15}$ En La métaphore vive [1975]. La Metáfora viva (1980). 
También pueden ser heterogéneos los protagonistas, puede ser un adversario, pueden ser los amigos, pero [lo importante es] que se ha construido, entre todos, una única historia. (Ricœur, 1994, m. 33:20-34:10).

Ricœur presenta el paralelismo entre dos géneros literarios (que se pueden utilizar en distintos ámbitos no propiamente literarios — como la historia o el derecho-, incluso alejados de lo literario - como la medicina-), la poesía — con la metáfora- y la narración — con la puesta en intriga de los acontecimientos-. Aunque pretende subrayar que no se trata solo de un paralelismo sino del principio (que no argumento) de la analogía en el método de la síntesis de lo heterogéneo, que él ubica en el nivel ontológico —como Kant-. (Ricœur, 1994, m. 34:00 - 35:05).

También es elaborar una síntesis de lo heterogéneo, en mi opinión, el ser conscientes de que vivimos siempre en un presente distendido, que procura sintetizar, en el presente de la iniciativa, los tres presentes: el del pasado, el del futuro y el instante puntual (o los instantes puntuales) del presente desde el que procuramos construir la síntesis.

Esta síntesis de lo heterogéneo se relaciona con la concordancia discordante utilizada por Ricœur en el primer tomo de Tiempo y narración -el arte de convertir en creadora la discordancia-. (Ricœur, 1994, m. 35:0535:15). La concordancia discordante - la discordancia concordante-, la síntesis de lo heterogéneo es capaz de sacar a la luz la instrucción sobre nuestra existencia: el lenguaje — como discurso creador-instruye la vida ${ }^{16}$.

Desde el principio (y podemos decir, desde las primeras obras de Ricœur) la cuestión clave es la capacidad del discurso creador de recrear las cosas con la redescripción y refiguración, la transfiguración: ofrecer una visión con sentido, como la enseñanza del símbolo. En esta misma línea se incluye el concepto de representación - tal y como Ricœur lo explica- tanto para la memoria como para el quehacer historiográfico (para el que Ricœur utiliza el término representacia).

Pienso que la dialéctica fundamental del lenguaje es luchar en estos dos frentes. Porque, en la medida en que el lenguaje se pone en suspensión a sí mismo, adquiere su potencia de redescripción, de refiguración, de transfiguración de lo real. Y es aquí donde encuentro la cuestión que he dejado planteada al principio, la cuestión de la representación, porque la representación no se consigue solo mediante la fuerza literaria del lenguaje, la de darnos una copia de las cosas, sino, justamente, en su

${ }^{16}$ Carlos Gómez Sánchez en su artículo de 2016, "La vida como narración”, recorre también el camino de la literatura como instructora de la vida, como facilitadora de métodos con los que entenderse a sí mismo. En su caso, retoma este planteamiento de Ricœur desde la perspectiva del psicoanálisis y de la ética. 
capacidad de recrearlas, en el nivel mismo del sentido y en el nivel del signo. (Ricœur, 1994, m. 40:00-40:42).

Para Ricœur, el lenguaje ocupa un papel primordial en la filosofía - y en la vida humana- por su capacidad de construir sentido ${ }^{17}$.

En esta conferencia de 1994, Ricœur conecta la imaginación, el lenguaje y el tiempo, y lo hace imbricando los tres ámbitos, plano sobre plano y en distintas dimensiones, de forma que, como resultado, obtiene una lectura de la experiencia humana del tiempo, a través del discurso creador, un texto que capta lo semejante para destilar sentido. La construcción del discurso creador — de texto- se convierte así en una creación de habitabilidad, "este espacio de habitabilidad posible que es el mundo del texto". (Ricœur, 1994, m. 48:17).

Por primera vez, Paul Ricœur se replantea la prioridad de la narración para expresar el devenir del tiempo, la historia de la identidad de los seres humanos, ya sea en el nivel individual o en el colectivo. Anunciado desde el principio de su discurso sobre la imaginación y la regla, pero desvelado en todo su potencial motivador al final de su discurso:

Quisiera terminar diciendo que [la narración] no agota la capacidad de decir el tiempo. Y quisiera decir, incluso, que esto finalmente quizá es lo contrario a lo que yo había escrito hace una decena de años, en Temps et Récit, la narrativa no tiene la última palabra sobre el sentido de nuestra existencia temporal. (Ricœur, 1994, m. 58:00-58:30).

De todas maneras, Ricœur, al final de los tres volúmenes, en la conclusión, ya había advertido sobre esta impotencia de la narración. Sin embargo, en 1994, el filósofo francés llega más lejos en la consideración sobre qué es el tiempo y cómo lo expresamos.

Y ¿por qué?, primero porque esencialmente todos los relatos no se ocupan más que de un fragmento del tiempo, el comienzo de una historia, la mitad de una historia, el final, un fragmento de tiempo. Incluso, si nosotros prolongamos estos fragmentos de tiempo, los unos tras los otros, en particular, en las grandes novelas, las novelas de aprendizaje, las novelas generacionales, en las que siguen como diversas generaciones, siempre ocurre de manera sesgada, se trata siempre del tiempo de cortes limitados. Pero, cuando reflexionamos sobre el tiempo, sobre el tiempo en singular, recordamos esa frase de Kant: "hay un único tiempo" [aunque hablemos de las "partes del tiempo"] [...]

Pienso que nosotros utilizamos este tiempo único solamente en la poesía; es la poesía la única capaz de abrazar no ya el tiempo como conjunto de medidas cronológicas o

${ }^{17}$ Para estas relaciones de la literatura con la producción del sentido, los mitos y el símbolo, se puede ver el estudio de sobre literatura y existencia de Sixto Castro (2012). 
como sucesión de fases de una historia, sino como la condición temporal del ser, el ser en el tiempo. El ser en el tiempo. (Ricœur, 1994, m. 58:00-59:49).

"L'être dans le temps" repite dos veces Paul Ricœur al final de su conferencia, como un eco que ha de perdurar para ser pensado e interiorizado.

\section{Cómo hablar de la experiencia del tiempo. Los tiempos intermediarios}

En mi investigación filosófica, defiendo que uno de los hilos fundamentales del pensamiento de Ricœur es el tema del tiempo, específicamente, la condición temporal del ser. Ricœur vuelve en La historia, la memoria y el olvido, al libro XI de las Confesiones de San Agustín para plantear y desarrollar la cuestión del tiempo y de la temporalidad.

Es a Agustín en primer lugar a quien debemos el tema de la tridimensionalidad de la temporalidad asignada al alma. Agustín recalca dos rasgos importantes, luego reinterpretados por Heidegger: la diáspora originaria de las tres dimensiones [...] y la misma primordialidad de las tres instancias (Ricœur, 2003, p. 463).

Para San Agustín, el tiempo presenta tres dimensiones (pasado, presente y futuro); estas tres dimensiones suponen una diáspora que arrastra el interior del ser humano ante el abismo de la "discordancia" (la distentio animi): es la desemejanza que hace gemir al ser humano (a su espíritu). Las tres instancias temporales se distribuyen a partir del centro, y el centro es el presente. "Es el presente el que estalla en tres direcciones, reduplicándose de alguna manera cada vez", dice Ricœur (2003, p. 463) leyendo a Agustín. En realidad, se trata de tres modalidades del presente: el presente del pasado, que se hace efectivo por la memoria; el presente del presente, que supone la visión atenta (la atención); y el presente del futuro, que toma cuerpo mediante la espera.

Es en el interior de la persona humana —en su "espíritu”, dice San Agustín- en donde están las vestigia — las imágenes-huellas-con las que podemos traer rastros del pasado; con las anticipaciones presentes de lo que aún no ha ocurrido podemos vislumbrar lo que puede suceder en el futuro. El presente del presente lo vivimos en profundidad por la atención ${ }^{18}$, con esta capacidad - a la vez activa y pasiva- podemos convertir el instante fugaz en una iniciativa transformadora que prepara el futuro y renueva, de alguna manera, el pasado ${ }^{19}$.

${ }^{18}$ Para la atención, se puede ver el artículo de Natalie Depraz (2015).

${ }^{19}$ Más detalles en el artículo sobre la crítica filosófica (Laguna, 2020). 
Paul Ricœur se irá dando cuenta, a lo largo del proceso de escritura que supone su obra, que lo importante en las dimensiones del tiempo - y en su distensión discordante pero creadora ${ }^{20}$ - no es el qué ni el dónde (dónde están los recuerdos...), sino el cómo vuelven -se traen- al presente (en el presente del pasado). Así lo expone en La Memoria, la Historia y el olvido, concretamente en su revisión del libro de Bergson Materia y memoria.

Una segunda especificidad del pensamiento de Ricœur respecto al tiempo está tomada también de forma reverente de San Agustín, sin embargo, partiendo de él, de la forma como habla de la experiencia humana del tiempo, se levanta más lejos filosóficamente. "No existe fenomenología de la memoria fuera de la búsqueda dolorosa de la interioridad". Todo el escrito de las Confesiones, en su conjunto supone la utilización de un género literario (una tipología textual), a la que se añaden otras - a manera de ramificaciones que completan el árbol (himnos de alabanza, súplica). Narrativa y poética de la interioridad para conocerse a sí mismo y para reconocerse ante una segunda persona con mayúsculas ante quien todos los recovecos de la vida están al descubierto. Los humanos, no obstante, han de servirse del método del relato autobiográfico y la poesía.

Justamente "la palabra creadora", más allá de la "palabra privada", será la puerta que abra y ensamble el tiempo humano - limitado, concreto, situado, individual, finito- con la eternidad — universal, que trasciende el espacio y el tiempo concreto, que se levanta por encima de lo individual para acoger las distintas alteridades-. La palabra creadora - palabra oral o composición escrita- es primero una palabra que busca, que se interro$\mathrm{ga}^{21}$, que escucha, lee e interpreta: "una palabra reflexiva, que es capaz de unir la memoria y la conciencia", como decía Ricœur.

La construcción simbólica del tiempo es un proceso entre la acción y la pasividad. Un proceso que necesita el lenguaje y sus estructuras, sus géneros literarios. Pero que también es pasividad (impresiones, huellas). Un proceso que necesita, para ser comprendido, las enseñanzas de la psicología y la sociología, de la literatura y de la historia, de la religión y la fenomenología para comprender esta configuración simbólica.

Ricœur, vivo más allá de la muerte, nos propone leer Temps et Récit ${ }^{22}$ —de principio a fin- de la misma manera que La Memoria, la Historia y el

${ }^{20}$ Porque es capaz de traer los tiempos no presentes al presente. Es nuestra condición histórica.

${ }^{21}$ Para la cuestión de la interrogación de la palabra creadora es fundamental el libro de O. Abel (2000).

22 Tiempo y narración I, (1995) [1983], Tiempo y narración II (1995) [1985], Tiempo y narración III (1996) [1985]. 
Olvido, (como él decía de Matière et Mémoire de Bergson). En una segunda travesía por la interpretación del tiempo y su imbricación con las variadas tipologías textuales que suponen el orden simbólico: un nivel de significado que abre a la persona hacia las distintas dimensiones temporales, más allá del presente. Una alteridad en la experiencia del tiempo que desembocará sobre una sabiduría práctica, la del reconocimiento del otro.

Ricœur explica que no es lo mismo "tiempo del mundo" que "tiempo de público o tiempo de la conmemoración” (Ricœur, 2003, p. 122). El tiempo público o de la conmemoración es el tiempo que tiene uno de sus momentos culminantes en la elaboración común del calendario, en cada sociedad. El ejemplo del calendario es significativo porque une el tiempo físico (cosmológico) y el tiempo interior (psicológico y fenomenológico) en el ámbito común de la sociedad y la cultura. Pero el tercer tiempo es un constructo que posee una función heurística que se abre más allá de los estudios de la historia (Laguna, 2019, p. 119).

Olivier Abel, en su estudio sobre el tiempo desde la perspectiva ética, habla, de manera acertada, de "figuras del tiempo intermediarias o mixtas", figuras del tiempo que son a la vez subjetivas y cosmológicas. El tiempo se expresa en "registros temporales diferentes". En este punto, como siempre en su hermenéutica de vía larga, Ricœur analiza las diferencias, mira los contextos concretos, se enfrenta a los problemas atendiendo a su diversidad y valorándola. Este es el modo de hacer filosofía también de su discípulo y amigo, Olivier Abel.

El tiempo humano, tiempo de la discordancia al que intentamos hacer concordar en las intrigas siempre parciales, es un tiempo contado. Paul Ricœur ha desplegado de esta manera unas figuras del tiempo intermediarias o mixtas, a la vez subjetivas y cosmológicas. El tiempo de los historiadores es a la vez un tiempo inscrito en un calendario cosmológico y un tiempo vivido, en el que los puntos de vista subjetivos diversos se reencuentran o se alejan (Abel, 2009, cap. 15) ${ }^{23}$.

\section{Reconstruir el tiempo de la historia: memoria, investigación y discurso creador}

La memoria y la mirada interior

En el año 2000 —el mismo año de la aparición de La Mémoire, l'Histoire, l'Oubli- Ricœur publicó un artículo decisivo en la prestigiosa revista de Historia: Annales. Histoire et Sciences Sociales. El texto fue primero una

${ }^{23}$ Traducción propia. 
conferencia pronunciada en L'École des Hautes Études de Sciences Sociales: "L'écriture de l'histoire et la représentation du passé" 24 " "La escritura de la historia y la representación del pasado"). Dice F. Dosse ${ }^{25}$ que "la invitación a esta prestigiosa conferencia fue excepcional, porque los historiadores en Francia se mantienen sistemáticamente a distancia de los filósofos" ${ }^{26}$.

De nuevo, Ricœur elaboró una filosofía práctica como guía y recomendación para las ciencias. Presentó un artículo atrevido, valiente, a la vez que sólido y colmado de sentido, con el rigor filosófico que la ciencia necesita integrar en su quehacer, con el fin de utilizar una metodología adecuada y elaborar una escritura que ofrezca, realmente, el resultado de su búsqueda. En primer lugar, con relación a este artículo y a la obra maestra de Ricœur sobre la historia (La Memoria, la Historia y el Olvido), diremos que, para la construcción de la historia, hemos de tener presente, antes que nada, la memoria y su funcionamiento. Aunque no se trate de una autobiografía y a pesar de que no contemos con testigos directos para "armar" la escritura de la historia.

En este punto, es preciso volver a san Agustín y sus escritos sobre el tiempo inmersos en las Confesiones, por un lado, un tiempo interno, subjetivo, que nace de la emoción del proceso de confesión autobiográfica, pero que, por otro lado, se abre al tiempo único, no fragmentado ni limitado de la eternidad (en los términos que Agustín lo expresa). Ricœur había explicado largamente en Tiempo y narración los enfrentamientos entre el tiempo cosmológico y el tiempo vivido, así como la necesidad de recurrir a un tercer tiempo intermedio, situado en los límites donde ambos tiempos se juntan, para explicar - por lo menos en parte- nuestra condición temporal.

En la conferencia de 1994 — sobre la imaginación y la regla-, el filósofo retoma esta explicación para subrayar la organización del método en la narrativa de la historia (la puesta en intriga del relato, el uso y la disposición de los tiempos), para preparar el avance de ideas nuevas:

Y es en esta articulación de un tiempo cronológico, cosmológico en el que despojamos el sentido en tanto que tal. Y, por otra parte, esta densidad de búsqueda de sentido en el interior del intervalo corto que se juega lo narrativo, porque lo narrativo guarda cualquier cosa del tiempo cronológico: hay un comienzo, un medio, un final, y, por otra parte, se trastoca — conmocionado- el orden de la sucesión: vemos los lapsos en flas, los actos de posibilidades de ideas y venidas. Y, por tanto, podemos decir que en el relato se va a construir la cohesión de una vida y la estructura de una

${ }^{24}$ Este artículo ha sido editado digitalmente en los últimos meses por los investigadores del Fonds Ricœur. Concretamente, escribe la nota editorial del texto, François Dosse.

${ }^{25}$ François Dosse ha profundizado en varios de sus escritos sobre la filosofía de la historia de Ricœur. Se puede ver, como síntesis, "El momento Ricœur" (2001).

${ }^{26}$ Cita del editorial del artículo publicado digitalmente por el Fonds Ricoeur (traducida). 
historia, en este intervalo entre el tiempo del mundo y el tiempo del alma. (Ricœur, 1994, m. 49:31-52:10).

Buscamos un intervalo entre el tiempo del mundo y el tiempo del alma. El tercer tiempo — cultural—, que necesitamos para elaborar la escritura de la historia, no se reduce al hecho de que el tiempo histórico es un tiempo intermedio entre el cosmológico y el fenomenológico, entre el tiempo físico y el tiempo vivido. Tiene un significado más amplio, que es preciso conocer para el trabajo de la historia. Se trata de la necesidad de tener en cuenta la cuestión de la memoria y, con ella, de la alteridad, ligada a la imagen y al recuerdo.

A la alteridad de los otros tiempos nos podemos aproximar, en principio, mediante la imagen y mediante el recuerdo, aunque la búsqueda del recuerdo supone una problemática subjetiva, psicológica, física. Cuando se encuentra, en los "palacios de la memoria", el recuerdo buscado, se vive una experiencia gratificante: la experiencia del reconocimiento. Y en todo este proceso, es decisiva la cuestión de la confianza, a pesar de que podemos equivocarnos, engañarnos a nosotros mismos, podemos no hacer bien el camino de regreso hacia "los lugares de la memoria", como decía Agustín en el libro XI de sus Confesiones. "Lo digo con firmeza, no tenemos nada mejor que la imagen-recuerdo en el momento del reconocimiento. Pero, ¿estamos seguros de que alguna cosa ha pasado más o menos tal y como se propone a nuestra mente en el proceso de recordar?" (Ricœur, 2000, p. 733).

La cuestión del sujeto de la memoria es crucial tanto en la memoria individual (para la identidad poético-narrativa personal) como en la memoria colectiva (para la sociología y la historia). ¿Quién recuerda? ¿Quién se representa las cosas pasadas?, se pregunta Ricœur (2000, p. 733).

\section{La energía de la búsqueda y la escritura de la historia}

Para la transición entre la memoria y la historia, el filósofo toma impulso - ante el auditorio de los historiadores expertos- y se apoya en las dificultades del recuerdo y la pragmática de la memoria para enfrentarse a la cuestión crucial de la representación histórica: medicina del tiempo individual para la salud del tiempo singular colectivo de la historia. La historia no puede compartir con la memoria el pequeño momento de felicidad que supone el reconocimiento que hace posible el recuerdo ("la sola y precaria garantía de fidelidad de la memoria”, p. 736).

La falta de la felicidad del reconocimiento del recuerdo, que sí tiene la memoria, la historia la suple con la energía de la búsqueda, según el título que le dio Heródoto. La búsqueda histórica, que suple al recuerdo mnemónico, ilumina desde aquí el 
conjunto de operaciones historiográficas sobre el largo trayecto horizontal desplegado de la fase documental a la fase escrituraria [de la escritura]”. (Ricœur, 2000, p. $737)^{27}$.

Dice Ricœur que las dificultades del conocimiento histórico ${ }^{28}$ comienzan con la ruptura que significa la escritura. Aunque la escrituraria, propiamente es la tercera de las tres fases del proceso historiográfico, se ha llamado, por parte de autores importantes, a todo el proceso "la escritura de la historia" 29 .

Las tres fases son las siguientes: 1. La documental, en los archivos. 2. La fase explicativa/comprensiva. 3. La propiamente escrituraria, en donde la cuestión de la representación cobra mayor protagonismo.

La toma de distancia en la confección de documentos (rudimentarios y con fines muy precisos al principio), en el paso de lo privado a lo público, posibilitó que la historia pudiera acceder a los hechos y la cultura del pasado (mediante las inscripciones y los distintos tipos de registros). La fase documental supone la intersección entre la memoria individual y la colectiva; el lugar de los límites entre ambas; corresponde (como las otras dos fases) al tercer tiempo que presentó Ricœur ya en Tiempo y narración ${ }^{30}$. Es un lugartiempo situado entre la naturaleza y la regla, entre lo personal y lo social, entre el tiempo fragmentado y el tiempo único (para Ricœur, también entre lo finito y la eternidad).

En la fase documental, el testigo y las huellas son los otros pilares de la investigación. De nuevo en este punto, Paul Ricœur pone en conexión la memoria individual con la historia. Por un lado, hemos de tener en cuenta la problematicidad que supone creer la versión de los testigos con su percepción particular y su recepción sesgada de los hechos, debido a las emociones, a las circunstancias, a su bagaje cultural o a su experiencia previa. Por otro lado (en la otra cara), tenemos la cuestión — primordial para Ricœurde la atestación. La atestación es una capacidad humana fundamental,

${ }^{27}$ Traducción propia del original francés del artículo de 2000 (del mismo modo, el resto de las citas).

${ }^{28}$ Para las relaciones entre la filosofía y la historia, desde la perspectiva de Ricœur, además de los textos de François Dosse señalados, se puede ver el artículo y la reseña de Daniel Ovalle (2011 y 2014).

${ }^{29}$ Ricœur señala el libro de Michel Certeau de 1975.

${ }^{30}$ Uno de los estudios del ámbito hispanoamericano que ha estudiado con mayor profundidad y acierto, a mi juicio, las cuestiones del límite entre la filosofía y la historia es Esteban Lythgoe. En la bibliografía se pueden ver sus aportaciones fundamentales: "La ruptura ontológica de La memoria, la historia y el olvido con respeto a Tiempo y narración” (2008), así como "Ricœur y la representación histórica" (2010). 
que el filósofo presenta, especialmente, en Sí mismo como otro $(1996)^{31}$, y en su último libro Caminos del reconocimiento (2005) ${ }^{32}$. Es lo único que nos queda respecto a la veracidad pretendida (deseada) de un testigo. La intención que podemos encontrar tanto en los testigos como en las huellas como en el archivo.

La confrontación de testimonios, además de crear la controversia entre los historiadores - purificando el proceso histórico- conduce a "la contestación, la crítica del testimonio marca el lugar a contracorriente del disenso y de su valor educativo en el plano de la discusión pública [...] (Ricœur, 2000, p. 737). Para que los testigos y sus testimonios pasen a la historia hace falta que su atestación se ponga por escrito y se recoja, en algún momento en los archivos.

Para la segunda fase, explicativa y comprensiva, hemos de retener de la primera el elemento de las huellas. Muchas de las huellas - también llamadas huellas documentales- "no son más que testimonios: vestigios, indicios materiales o signos abstractos [...]. Es lo que Ginzburg llama el paradigma de los indicios, común a todas las disciplinas de conocimiento directo o conjetural, de la medicina y de la psiquiatría a la novela policiaca". (Ricœur, 2000, p. 738).

La interpretación de las huellas - como indicios- establece una semejanza en el método entre el quehacer histórico y la búsqueda del tiempo pasado a nivel individual, a partir de la memoria. Sin embargo, supone, del mismo modo, una identidad con respecto al principio del tiempo distendido, principio que investigo en mi tesis doctoral.

La fase documental se integra - de manera eficaz y productiva- con la fase de explicación y comprensión, cuando el investigador (o grupo de investigadores) consigue, con todos los recursos de la fase 1 , construir un gran documento globalizante que "puede ser interrogado por el historiador a fin de encontrar la información [que necesita] sobre el pasado, a la luz de una hipótesis de explicación y de comprensión”. (Ricœur, 2000, p. 738).

En la fase 2, la cuestión de la representación del pasado ${ }^{33}$-que es un asunto, primero, de la memoria individual, como hemos dicho- cobra un doble papel relevante: por un lado, reconstruir de alguna forma el pasado; y, en el otro extremo, se usa el concepto de representación para "designar

\footnotetext{
${ }^{31}$ Original de 1990.

32 Original de 2004 (su último libro publicado en vida).

${ }^{33}$ Para la cuestión de la representación del pasado desde la perspectiva de Ricœur, es interesante el artículo de D. Ovalle de 2011.
} 
las creencias y las normas que confieren una articulación simbólica a la constitución del vínculo social y a la formación de identidades [colectivas]". (Ricœur, 2000, p. 741).

Las duraciones múltiples, escalas de duración, ritmo temporal ${ }^{34}$, así como otras escalas y micro-análisis, son construcciones que reconstruyen "la condición histórica de los humanos, este referente último de la investigación histórica” (Ricœur, 2000, p. 741).

Estamos ya en la tercera fase, la escritura de la historia. Aunque la fase escrituraria no se añade a las otras, sino que "acompaña a cada una de las etapas” (p. 742). El discurso de la historia, según este camino de búsqueda, no tiene que ser un discurso verdadero, al estilo de las ciencias exactas, - dice Ricœur- sino un discurso que se sitúa en una intención de verdad. (p. 745).

Para explicar que entiende por representación en el quehacer historiográfico, Paul Ricœur utiliza el término representancia: un concepto clave en el que une, de nuevo, memoria e historia; un constructo con el que se sitúa en el límite, en la búsqueda y la aproximación. ¿Puede ser mantenido el pacto de lectura sobre el que descansa la escritura de la historia?, se pregunta Ricœur ante los historiadores:

Responder sí es testimoniar a favor de la intencionalidad reguladora de la investigación histórica: la intención de tender y, si es posible, atender a lo que fue el caso, el acontecimiento. Yo propuse en Temps et Récit el término "representancia" para señalar el vigor de esta intención-pretensión. La idea que recubre la palabra es, a la vez, la de una suplencia y la de aproximación. (Ricœur, 2000, p. 745).

Ricœur concluye su conferencia uniendo memoria e historia, precisamente, a través de la cuestión de la representación: el problema de la representación del pasado no comienza con la historia, sino que los problemas empiezan con la memoria. Representar algo que existía antes y que ahora ya no está presente.

En nuestra historia, nuestras construcciones son lo mejor de las reconstrucciones. Es de tales reconstrucciones [...], hechas con intención, pretensión, deseo, por las que medimos el grado de fiabilidad, conjugando la interpretación con la intención de verdad. (Ricœur, 2000, p. 746).

El filósofo hermeneuta ha llegado a la palabra fundamental, el término definitivo que une el lenguaje con la historia a cuenta del tiempo: la interpretación. Y, ante el público de historiadores celosos de su ciencia y de su método riguroso, lanza la flecha que llega a las profundidades:

\footnotetext{
${ }^{34}$ Tratadas pormenorizadamente por Braudel y su escuela.
} 
Interpretación. El vocablo difícil es lanzado. Pero, presumir y asumir la solidaridad entre interpretación y verdad en historia es decir más que poner juntas la objetividad y la subjetividad, como se decía antes. Si no queremos solamente psicologizar o moralizar la intención historiadora, por ejemplo, señalando los intereses, los prejuicios, las pasiones del hombre historiador, celebrando sus virtudes de honestidad y modestia, incluso de humildad, entonces, es necesario marcar el carácter epistémico de la interpretación. (Ricœur, 2000, p. 746).

La interpretación no es lo opuesto a la búsqueda de la verdad en la historia. Al contrario, es una operación necesaria —en cada uno de los estadios del proceso historiográfico- para mantener y fomentar el deseo de verdad en la construcción histórica.

¿Qué consigue la historia tras la energía de su búsqueda, con los instrumentos que comporta su proceso de representancia y la incorporación adecuada de la interpretación honesta en cada paso de la investigación y la escritura? El beneficio que obtiene la historia — su manera especial de reconocimiento del pasado- es "el poder de ampliar la mirada en el espacio y en el tiempo, la fuerza de la crítica en el orden del testimonio; la fuerza de la explicación y de la comprensión, en el dominio retórico del texto y, sobre todo, el ejercicio de la equidad respecto a las reivindicaciones concurrentes de las memorias heridas y a veces ocultadas [...]”. (Ricœur, 2000, p. 747).

\section{Conclusiones}

Hemos puesto en relación dos temas fundamentales del pensamiento de Ricœur: el discurso creador y la condición temporal del ser humano. Me he propuesto pensar estos dos ámbitos de estudio de manera unificada, como dos cuestiones antropológicas que se conectan mediante una textura indisoluble en la obra de Ricœur.

En mi investigación, considero a Paul Ricœur como el filósofo del tiempo, y esta perspectiva es clave para interpretar en qué sentido se unen el discurso creador y la experiencia temporal de ser humano. A mi juicio, Ricœur piensa, habla y escribe, siempre, filosofía del tiempo. No obstante, conoce perfectamente la aporía de un concepto abstracto y escurridizo hasta el extremo, y sabe que no debe teorizar ni recoger en un pañuelo el agua que fluye.

En Tiempo y narración, el filósofo pensó el tiempo desde la organización que juega con los fragmentos del tiempo (de los personajes) y que construye la intriga. Allí estableció — hablando del discurso de la historia- que hay un tercer tiempo, más allá del cosmológico y del fenomenológico, un tercer 
tiempo cultural e histórico, en la intersección del tiempo físico y el tiempo vivido.

Considero que la conferencia de 1994, "La imaginación y la regla" - aunque no fue puesta por escrito después, para ser publicada por parte del autor-, contiene una aportación decisiva de la filosofía de Ricœur: el autor lanzó en ella una advertencia digna de ser tomada en cuenta en su obra posterior (aunque ya había pensado sobre ello — sobre todo en las conclusiones de Temps et Récit). En mi opinión, todos los escritos de Ricœur a partir de 1994 suponen la profundización en esta idea pronunciada en diciembre, al final de su discurso, en la Universidad de Jerusalén: "la poesía - parece- que es la única capaz de abrazar no ya el tiempo como conjunto de medidas cronológicas o como sucesión de fases de una historia, sino como la condición temporal del ser. El ser en el tiempo". La poesía y lo poético, en el universo filosófico de Ricœur, indican la capacidad (y el modo) del discurso creador que ofrece sentido.

Desde ese momento clave en su filosofía, Ricœur, a mi juicio, nos muestra dos caminos para el acercamiento a la comprensión de la condición temporal del ser: uno el modo de expresión de "los otros géneros literarios" 35 (no solo la narración). Estas tipologías textuales muestran el proceso del devenir del ser individual y colectivo, en especial, los textos que recogen sabiduría intemporal (como los textos bíblicos, entre otros) y los textos filosóficos que buscan transmitir sentido a través de los siglos, los lugares y las personas. El otro es el camino que acompaña al quehacer histórico, dando luz en cada una de sus etapas, alumbrando la acción necesaria en el presente así como la promesa de futuro.

La construcción simbólica del tiempo es un proceso entre la acción y la pasividad. Este proceso necesita ser dicho: utiliza los instrumentos del lenguaje, con su estructura y sus modos textuales. Pero, además, la construcción (y la reconstrucción) simbólica del tiempo requiere que utilicemos las herramientas de las disciplinas humanas, sociales y científicas. En especial, la historia, la literatura, la psicología, la sociología, incluso, la religión, por la sabiduría - a la vez contextualizada y atemporal- que encierran los textos sagrados.

Ricœur nos pide, desde su obra ya cerrada, una segunda travesía por la comprensión del tiempo; nos invita a abrirnos desde el presente a otras dimensiones temporales, como ha enseñado la fenomenología, pero con

${ }^{35}$ El segundo número del año 2020 de la Revista Études Ricœuriennes, Ricœur Studies, está dedicado al tema del tiempo. Se puede ver, en especial, O. Abel (2020). 
las herramientas específicas de la hermenéutica — permeadas de tipologías textuales, de lecturas y de interpretación-. Se trata de aprender a vivir, así, una alteridad en la experiencia del tiempo y del espacio que conduce a la sabiduría practica de reconocimiento del otro.

Para explicar esta tarea única e ingente de acción creadora, Ricœur elaboró, con tesón y esmero, los artículos que fueron a parar - como ríos- a la mar inmensa que es su libro La Memoria, la Historia y el Olvido. Hemos analizado uno de estos artículos, cuyo origen fue la conferencia que Ricœur pronunció ante los profesionales de la historiografía de París, en el año 2000. Porque, en el marco de la historia, también encontramos el protagonismo del discurso creador, que aquí toma el nombre de escritura de la historia: una escritura que, según Ricœur - y otros estudiosos de la historiografía-, abarca las tres fases del proceso en la construcción de la historia (la documental, la de la representación y la de la escritura, propiamente).

Consideramos que el poder de la imaginación creadora — que se expresa en el tiempo y con marcas formales temporales- cobra en el estudio de la historia una riqueza especial (se trataría de una cierta poética de la historia que es capaz de expresar la condición temporal del ser humano, uniendo, como lo hace Paul Ricœur en su discursos filosóficos, memoria e historia, lo individual y lo colectivo - lo personal y los social—, la naturaleza y la regla, el tiempo fragmentado y el tiempo único, lo finito — limitado- y la eternidad (que se encuentra de alguna manera en ciertos discursos creadores).

En todo caso, el filósofo avisa a los historiadores de que la interpretación —el discurso creador de la historia- ha de estar presente en cada una de las fases, si queremos que la historia sea capaz de expresar quiénes han sido los individuos y las sociedades; cómo se han desarrollado los acontecimientos y por qué, también con qué consecuencias. Ricœur se presenta como el filósofo del tiempo que las ciencias humanas y sociales de comienzos del siglo XXI deberían tener en cuenta.

\section{Bibliografía}

Abel, O., L'éthique interrogative, herméneutique et problématologie de notre condition langagière, Paris, PUF, 2000.

Abel, O., "Ethique du temps", in Introduction à l'éthique, ed. Jean-Daniel

Causse et Denis Müller, Genève, Labor et Fides, 2009, chapitre 15. Abel, O., "Les styles du temps". Études Ricouriennes / Ricour Studies, 11/2 (2020), 87-110. 
Agís Villaverde, M., "Paul Ricœur: los caminos de la hermenéutica", Revista Agora. Papeles de Filosofía, (2006), 25/2, 25-44.

Amalric, J.L., "L'Imagination poético-pratique dans l'identité narrative ", Études Ricouriennes / Ricour Studies, 3/2 (2012), 110-127.

Bachelard, G., La poética del espacio, Madrid, FCE, 2012 [1957].

Barros de Oliveira, R., "Entre philosophie et linguistique. Autour de "Philosophie et langage” de Paul Ricœur, Études Ricœuriennes / Ricœur Studies, 1 (2020), 65-85.

Castro, S., "Literatura y existencia", Thémata: Revista de filosofía (2012), 45, 437-450.

Certeau, M. de, L'écriture de l'histoire, Paris, Gallimard, 1975.

Depraz, N., "Attention et surprise. Paul Ricœur au-delà”. Alter, Revue de phénoménologie 23 (2015), 261-277.

Dosse, F. "Le moment Ricœur de l'opération historiographique", Vingtième Siècle, Revue d'histoire, 69, (2001), 137-152.

Gómez Sánchez, C., "La vida como narración (Aranguren y Ricœur)”, Daimon. Revista Internacional de Filosofía, 68 (2016), 67-83.

Inizan, Y., "La unidad de la vasta esfera poética”, Études Ricouriennes / Ricour Studies, 7/2 (2016), 111-123.

Laguna, M., "El tiempo en la hermenéutica de Paul Ricœur. Las capacidades humanas entre el instante y la distensión", Estudios Filosóficos LXVIII (2019), 103-124.

Laguna, M., "La crítica filosófica en la escritura del tiempo de Paul Ricœur”. En Nicolás, J.A., Whanón, S. y Romero, J.M. (eds.), Crítica y hermenéutica. Perspectivas filosóficas, literarias y sociales, 2020, pp. $175-186$.

Lythgoe, E., "La ruptura ontológica de La memoria, la historia y el olvido con respeto a Tiempo y narración", Escritos de Filosofía, Academia Nacional de Ciencias, 47, (2008), 273-290.

Lythgoe, E., "Ricœur y la representación histórica", Revista ALEA, 8 (2010) 29-76.

Lythgoe, E., "El papel de la imaginación en La memoria, la historia, el olvido de Paul Ricœur", Dianoia, Anuario de Filosofía 73, (2014), 73-88.

Ovalle, D., "Le travail de la mémoire en Paul Ricœur: la significación como aporte epistemológico para el estudio de la historia", Historia 396, 2 (2011). 265-280.

Ovalle, D., "François Dosse, Paul Ricour-Michel de Certeau: la historia entre el decir y el hacer. Buenos Aires: Nueva Visión, 2009, 128 págs.”, Historiografías, 7 (2014), 125-129.

Ricœur, P., La metáfora viva. Madrid, Cristiandad, 1980 [1975]. 
Ricœur, P., "Imagination et métaphore". Revue de Psychologie Médicale, 14 (1982). Publiée on-line sur le Fonds Ricœur: P. Ricœur, "Imagination et métaphore", 1982, IIA365a, Fonds Ricœur. Consulté le 26 août 2020 : https://omekas.obspm.fr/s/psl/ark:/18469/mx1g

Ricœur, P., "L'imagination et la règle", conférence de Paul Ricœur pour l'inauguration du Centre de recherche sur la culture française, Université hébraïque, Jérusalem (15 décembre 1994), Canal YouTube du Fonds Ricœur: https://www.youtube.com/watch?v=PmSmSjZn9e4

Ricœur, P., Tiempo y narración I. La intriga y el relato histórico, Madrid, Siglo XXI, 1995 [1983].

Ricœur, P., Tiempo y narración, II. La configuración del tiempo en el relato de ficción, Madrid, Siglo XXI, 1995 [1985].

Ricœur, P., Tiempo y narración, III. El tiempo narrado, Madrid, Siglo XXI, 1996 [1985].

Ricœur, P., Sí mismo como otro, Madrid, Siglo XXI, 1996 [1990].

Ricœur, P., "L'écriture de l'histoire et la représentation du passé", Annales. Histoire. Science sociales 4 (2000), 731-747. Publiée on-line sur le Fonds Ricœur. Consulté le 19 août 2020 : https://omekas.obspm.fr/s/ psl/ark:/18469/mx61

Ricœur, P., "La imaginación en el discurso y en la acción”, en Del texto a la acción. Ensayos de hermenéutica II, México, FCE, 2002, pp. 197-218 [1986].

Ricœur, P., La historia, la memoria y el olvido. Madrid, Trotta, 2003 [2000].

Ricœur, P., Caminos del reconocimiento. Madrid, Trotta, 2005 [2004].

Wahnón, S., "La función crítica de la interpretación literaria". Sociocriticism, $1 / 2$ (2011), 127-164. 